J. Clin. Chem. Clin. Biochem.

Vol. 24, 1986, pp. 457-463

(C) 1986 Walter de Gruyter \& Co.

Berlin - New York

\title{
Human Apolipoprotein C-II Quantitation by Sandwich Enzyme-Linked Immunosorbent Assay
}

\author{
By J. Bury, G. Michiels and Maryvonne Rosseneu \\ Department of Clinical Chemistry, A. Z. St-Jan, Ruddershove, Brugge, Belgium
}

(Received October 9, 1985/February 13, 1986)

Summary: A specific, sensitive and accurate, non competitive enzyme-linked immunosorbent assay was developed for the quantitation of human apolipoprotein C-II. Using apolipoprotein C-II and apolipoprotein C-III immunosorbent columns, monospecific anti-apolipoprotein C-II'antibodies were prepared for coating and for the preparation of a peroxidase-antibody conjugate. The assay is sensitive down to $0.25 \mathrm{ng}$ apolipoprotein C-II per assay and precise, with mean intra- and inter-assay coefficients of variation of $3.1 \%$ and $7.9 \%$ respectively. The apolipoprotein C-II concentrations in normolipaemic and hyperlipaemic plasma were not affected by delipidation, and increased only slightly after treatment with detergents or urea.

The mean plasma apolipoprotein C-II concentration in a group of 30 normolipaemic subjects, was $33.1 \pm$ $7.5 \mathrm{mg} / 1$. All hypertriglyceridaemic subjects had significantly elevated apolipoprotein C-II plasma concentrations, which were most pronounced in Fredrickson type III and type V patients.

The apolipoprotein C-II profiles, obtained by column fractionation of 6 normolipaemic and 11 hypertriglyceridaemic plasmas, demonstrated a shift of apolipoprotein C-II towards the triglyceride-rich lipoproteins in hypertriglyceridaemic subjects.

\section{Bestimmung von Apolipoprotein C-II vom Menschen mit einem Sandwich-Immunosorbent-Assay}

Zusammenfassung: Ein spezifischer, empfindlicher und genauer nicht-kompetitiver Enzyme-Linked-Immunosorbent-Asssay wurde für die Quantifizierung von menschlichem Apolipoprotein C-II entwickelt. Mit Apolipoprotein C-II und Apolipoprotein C-III Immunosorbent-Säulen wurden monospezifische anti-Apolipoprotein C-II-Antikörper für die Beschichtung sowie ein Peroxidase-Antikörper-Konjugat hergestellt. Die Empfindlichkeit des Bestimmungsverfahrens beträgt bis zu 0,25 ng Apolipoprotein C-II. Der Assay ist präzis mit mittleren Variationskoeffizienten von 3,1\% innerhalb der Serie und 7,9\% von Tag zu Tag.

Der Apolipoprotein C-II-Gehalt in normolipämischen und hyperlipämischen Plasmen wurde von der Lipidabtrennung nicht beeinflußt und nahm nach Behandlung mit Detergentien oder Harnstoff nur ein wenig zu. Diè mittlere Apolipoprotein C-II-Konzentration im Plasma einer Gruppe von 30 normolipämischen Probanden war 33,1 $\pm 7,5 \mathrm{mg} / 1$. Alle hypertriglyceridämischen Probanden hatten signifikant erhöhte Apolipoprotein C-II Konzentrationen im Plasma, besonders bei Fredrickson Type III und Type V. Die Apolipoprotein C-IIProfile, die durch Säulenfraktionierung von 6 normolipämischen und 11 hypertriglyceridämischen Plasmen erhalten wurden, zeigten eine Verschiebung von Apolipoprotein C-II zu den triglyceridämischen Lipoproteinen in hypertriglyceridämischen Plasmen.

\section{Introduction}

The apolipoprotein $\mathrm{C}$ polypeptides play a significant role in the catabolism of human serum triglyceride- rich lipoproteins (1). When these lipoproteins are secreted by either the gut or the liver, they acquire $C$ and $\mathrm{E}$ apolipoproteins from the high density lipopro- 
teins (HDL) (1). One of these apolipoproteins, namely apolipoprotein C-II, is required for maximal activation of lipoprotein lipase, the enzyme which hydrolyses the triglycerides in chylomicrons and in very low density lipoproteins (VLDL) (2). The importance of apolipoprotein C-II as a cofactor for lipoprotein lipase was demonstrated in apolipoprotein CII-deficient patients, where the extreme triglyceride plasma concentrations could be normalised by infusing normolipaemic plasma as a source of apolipoprotein C-II (3).

The amino acid sequence of apolipoprotein C-II was first reported by Jackson et al. (4) and subsequently revised by Hospattankar et al. (5). Apolipoprotein CII consists of 79 amino acid residues with a molecular weight of 8916 daltons (5).

Precise quantitation of the apolipoproteins is required in order to assess their role in lipoprotein metabolism. The specific quantitation of human apolipoprotein CII has been reported using radioimmunoassays (RIA) $(6-8)$, electro-immunodiffusion assay $(\operatorname{EID})(9,10)$, immunonephelometry (INA) (11) and a competitive enzyme immunoassay (12). Here we describe the development and the evaluation of a sandwich enzymelinked immunosorbent assay (ELISA), specific for the quantitation of apolipoprotein C-II in human plasma and its lipoprotein fractions. The results obtained by this technique are compared with those reported in the literature.

\section{Materials and Methods}

Isolation of apolipoproteins and production of antisera

The VLDL were obtained by ultracentrifugal flotation from a plasma pool of hypertriglyceridaemic patients. After delipidation with ether/ethanol, the apolipoprotein VLDL was fractionated on a column of Sephacryl S 200 as described previously (13). The fractions containing apolipoprotein $C$ were collected and further purified by chromatofocussing on a column $(50 \times$ $1 \mathrm{~cm}$ ) of polybuffer exchanger 94 (Pharmacia Fine Chemicals, Uppsala, Sweden) as described by Knipping et al. (14). The column was equilibrated with $25 \mathrm{mmol} / \mathrm{l}$ histidine $\mathrm{HCl}$ buffer pH 5.5, containing $6 \mathrm{~mol} / 1$ urea, freshly prepared and deionized, then eluted with polybuffer 74 , diluted $1: 8$ with $6 \mathrm{~mol} / 1$ urea, and adjusted to $\mathrm{pH} 4.0$ with $0.01 \mathrm{~mol} / \mathrm{l} \mathrm{HCl}$. Apolipoproteins $\mathrm{C}$-II, C-III ${ }_{1}$ and $\mathrm{C}-\mathrm{III}_{2}$ were respectively eluted at $\mathrm{pH} 4.67 \pm$ $0.05,4.56 \pm 0.10$ and $4.29 \pm 0.06(\mathrm{~N}=6)$. Apolipoprotein $\mathrm{C}-\mathrm{III}_{0}$, which eluated at $\mathrm{pH} 4.73 \pm 0.04$ contaminated the apolipoprotein C-II fraction. A narrow range of apolipoprotein C-II-containing fractions was selected for further use as a primary standard and immunogen. As determined by a specific ELISA (15) the apolipoprotein C-III contamination of this apolipoprotein C-II preparation was $<5 \%$.

To remove polybuffer and urea from the apolipoprotein C-II preparation, proteins were precipitated by $60 \mathrm{~g} / 1$ trichloroacetic acid in the presence of sodium deoxycholate, as proposed by Bensadoun \& Weinstein (16). Apolipoprotein C-II was resolubilized in $20 \mathrm{mmol} / \mathrm{l}$ sodium phosphate buffer $\mathrm{pH} 8.0$, extensively dialysed against $5 \mathrm{mmol} / \mathrm{l} \mathrm{NH}_{4} \mathrm{HCO}_{3}$, lyophilized and stored at $-20^{\circ} \mathrm{C}$ under nitrogen.
The purified apolipoprotein C-II was identified by its electrophoretic mobility on isoelectric focussing in $8 \mathrm{~mol} / \mathrm{l}$ urea and on polyacrylamide gels containing $1 \mathrm{~g} / 1$ sodium dodecyl sulphate (17), its immunological properties on immunodiffusion with antisera against apolipoproteins A-I, A-II, B, C-II, C-III, and $E$, and by its amino acid composition which agreed with that reported by Hospattanker et al. (5). Rabbits were immunised subcutaneously as described for apolipoprotein C-III (13).

Specific apolipoproteins A-I, A-II, B, C-III and E and their specific antisera were isolated from human $\mathrm{HDL}$ and VLDL as described elsewhere $(13,18-20)$.

Preparation of the coater and the enzyme-antibody conjugate

An apolipoprotein C-II-Sepharose column was prepared by covalent linkage of $420 \mu \mathrm{g}$ of the apolipoprotein C-II preparation (dissolved in $0.1 \mathrm{~mol} / 1 \mathrm{NaHCO}_{3} \mathrm{pH} 8.3$, containing 0.5 $\mathrm{mol} / \mathrm{l} \mathrm{NaCl}$ ) to $5 \mathrm{~g} \mathrm{CNBr}$-activated Sepharose $4 \mathrm{~B}$ as described for apolipoprotein A-I (19). Anti human apolipoprotein C-II immunoglobulins, used for coating, were isolated from rabbit antisera by immunosorbent affinity chromatography using standard techniques (19).

To produce a monospecific enzyme-antibody conjugate, contaminating anti-apolipoprotein C-III antibodies were removed by immunoaffinity chromatography on an apolipoprotein C-IIISepharose column (15). Subsequently the monospecific antiapolipoprotein C-II immunoglobulins were covalently linked to horse radish peroxidase (EC 1.11.1.7) using a modification of the periodate coupling procedure $(19,21)$. This conjugate, stored at $-20^{\circ} \mathrm{C}$ with an equal volume of glycerol, was stable for at least six months.

\section{Apolipoprotein C-II quantitation by sandwich ELISA}

The sandwich ELISA for apolipoprotein C-II was performed as for other apolipoproteins $(15,18,19)$ with the following modifications. Coating was performed, using a coating concentration of $10 \mathrm{mg} / \mathrm{l}$. Plasma samples and conjugates were diluted 3000 -fold and 10000 -fold respectively.

Calibration curves were obtained from the appropriate dilutions of a freshly prepared apolipoprotein C-II solution, from which the protein concentration was quantitated by several techniques including: quantitative amino acid analysis, phenylalanine quantitation by high performance liquid chromatography after protein hydrolysis (22), protein determination according to Bradford, using bovine serum albumin as standard (23) and absorbance measurements of the pure protein at $280 \mathrm{~nm}$, using a molar lineic absorbance of $1290 \mathrm{~m}^{2} / \mathrm{mol}$.

The results of the 3 control techniques were in good agreement with the quantitative amino acid analysis, which was considered as a reference technique (100\%). The apolipoprotein C-II concentration in the primary standard was determined by the phenylalanine quantitation, the Bradford analysis and the absorbance measurement; the resulting values were $99.96 \%$, $74.89 \%$ and $126.01 \%$ of the value from the quantitative amino acid analysis, respectively.

\section{Subjects}

Disodium EDTA plasma $(1 \mathrm{~g} / \mathrm{l})$ was collected from normal and hyperlipaemic subjects after an overnight fast. 5,5'-Dithio(2nitrobenzoic acid) (Sigma Chem. Co. $2 \mathrm{mmol} / \mathrm{l}$ ), Trasylol (Bayer, Leverkusen, F. R. G., $\left.10^{4} \mathrm{IU} / \mathrm{l}\right)$ and sodium azide (0.2 $\mathrm{g} / \mathrm{l}$ ) were added as a lecithin : cholesterol acyltransferase inhibitor, protease inhibitor and preservative, respectively. Plasma was stored at $-20^{\circ} \mathrm{C}$ for less thian three months before analysis. 
Subjects were classified according to Fredrickson (24), and selected as described previously (18).

Apolipoprotein C-II distribution and analytical techniques

Lipoproteins were separated from fresh plasma by gel filtration on a Sepharose $6 \mathrm{~B}-\mathrm{CL}$ column or by gradient ultracentrifugation as previously described $(15,25)$. Apolipoprotein C-II was assayed in all fractions using the ELISA described above.

The protein content of lipoproteins was measured by the Lowry technique (26), using bovine serum albumin as a spectrophotometric standard. Lipids were determined enzymatically (25). Apolipoproteins A-I, B, C-III and E were determined as previously described $(15,18-20)$.

\section{Results}

Standardization and sample pretreatment

A standard curve, constructed with purified apolipoprotein C-II as a primary standard (fig. 1), was used to calibrate a serum pool from normolipaemic donors. This serum pool was then aliquoted and stored at $-20^{\circ} \mathrm{C}$, and subsequently used as a suitable secondary standard and control (19). The calibration curves, obtained from plasma of normolipaemic and hyperlipaemic (triglycerides $5.4 \mathrm{~g} / \mathrm{l}$; cholesterol 4.1 $\mathrm{g} / \mathrm{l}$ ) individuals were parallel to that of the primary standard (fig. 1).

To investigate the influence of delipidation or sample pretreatment with detergents or denaturants on the plasma apolipoprotein C-II concentrations, 12 normolipaemic and hyperlipaemic plasmas were either delipidated with diisopropylether/n-butanol (27) or exposed to $4 \mathrm{~mol} / \mathrm{l}$ urea or to $1 \mathrm{~g} / \mathrm{l}$ sodium dodecylsulphate.

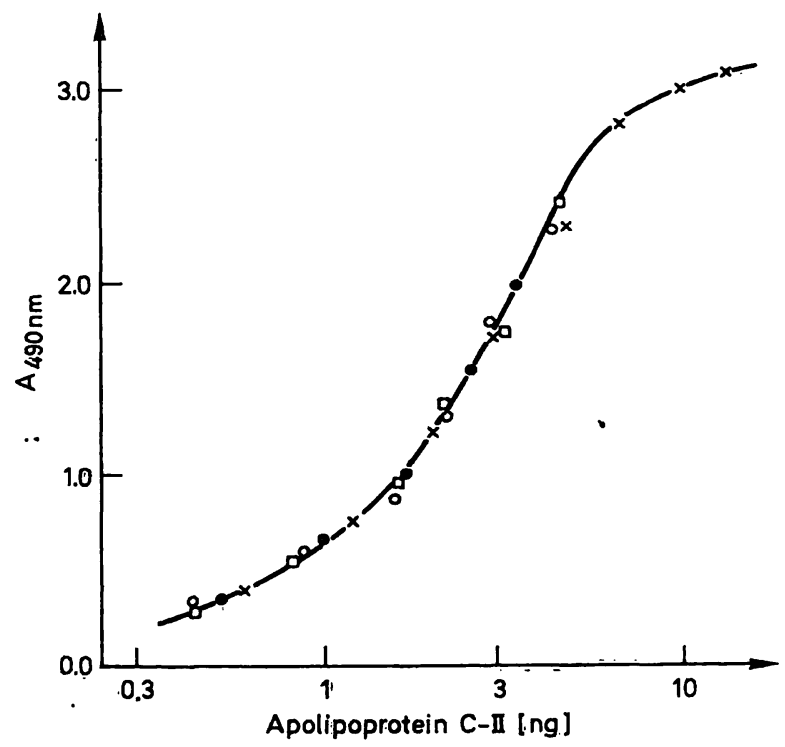

Fig. 1. Calibration curves for purified apolipoprotein C-II (x), human normolipaemic plasma (๑), normolipaemic delipidated plasma $(0)$ and hypertriglyceridaemic plasma (ㅁ)
The apolipoprotein C-II yield, expressed as the apolipoprotein C-II concentration after treatment $\times 100 \% /$ the apolipoprotein C-II concentration in native plasma, amounted to $98.8 \pm 7.8 \%$ after delipidation, $114.7 \pm 6.0 \%$ after incubation with the detergent and $111.4 \pm 5.0 \%$ after incubation with urea. The shape of the standard curve, constructed with plasma, was not modified by the above treatments (fig. 1).

Four plasma samples were diluted $1: 2$ in a chylomicron-like triglyceride micro-emulsion (Intralipid $20 \%$, Kabi Vitrum Stockholm Sweden) and incubated 1 hour at $37^{\circ} \mathrm{C}$. Apolipoprotein C-II recovery as determined by ELISA, was $102.3 \pm 7.5 \%$.

These data therefore suggest that the apolipoprotein C-II epitopes in native lipoproteins are fully exposed to the polyclonal antibodies used in our ELISA assay, avoiding the need for sample pretreatment.

The calibration curves, obtained with lipoprotein fractions, freshly isolated from plasma by sequential ultracentrifugation, paralleled the standard curve constructed with purified apolipoprotein C-II (fig. 2). Identical curves were obtained after lipoprotein delipidation. On the basis of their total protein content, chylomicrons, VLDL, LDL and HDL contained respectively $16.3 \%, 6.8 \%, 0.26 \%$, and $0.67 \%$ apolipoprotein C-II.

\section{Analytical variables}

The ELISA is sensitive down to $0.25 \mathrm{ng}$ apolipoprotein C-II per assay with a working range of 0.5 to $5 \mathrm{ng}$ (fig. 1). Using a 3000 -fold dilution, this range corresponds to apolipoprotein C-II plasma concentrations between 15 and $150 \mathrm{mg} / \mathrm{l}$. The standard curve can be fitted to a parabola by least squares analysis $(r=0.9977 \pm 0.0023, N=30)$.

The selectivity of the ELISA for apolipoprotein C-II was investigated, by constructing curves with purified apolipoproteins A-I, A-II, B, C-II, C-III, $\mathrm{E}$ and human albumin. As shown in figure 2 , the crossreactivity of these antigens with the monospecific anti-apolipoprotein C-II conjugate was $<0.01 \%$, $<0.01 \%, 0.25 \%, 100.00 \%, 0.25 \%, 0.08 \%$ and $<0.01 \%$ respectively. The negative response of purified apolipoprotein $\mathrm{C}-\mathrm{III}_{2}$, obtained by chromatofocussing or by ion exchange chromatography of VLDL apolipoprotein C (13), confirms the monospecificity of the apolipoprotein C-II ELISA.

Plasma samples with low, intermediate and high apolipoprotein lipoprotein C-II concentrations were analysed twelve times on the same day and on sixteen separate days to calculate the assay precision. As 


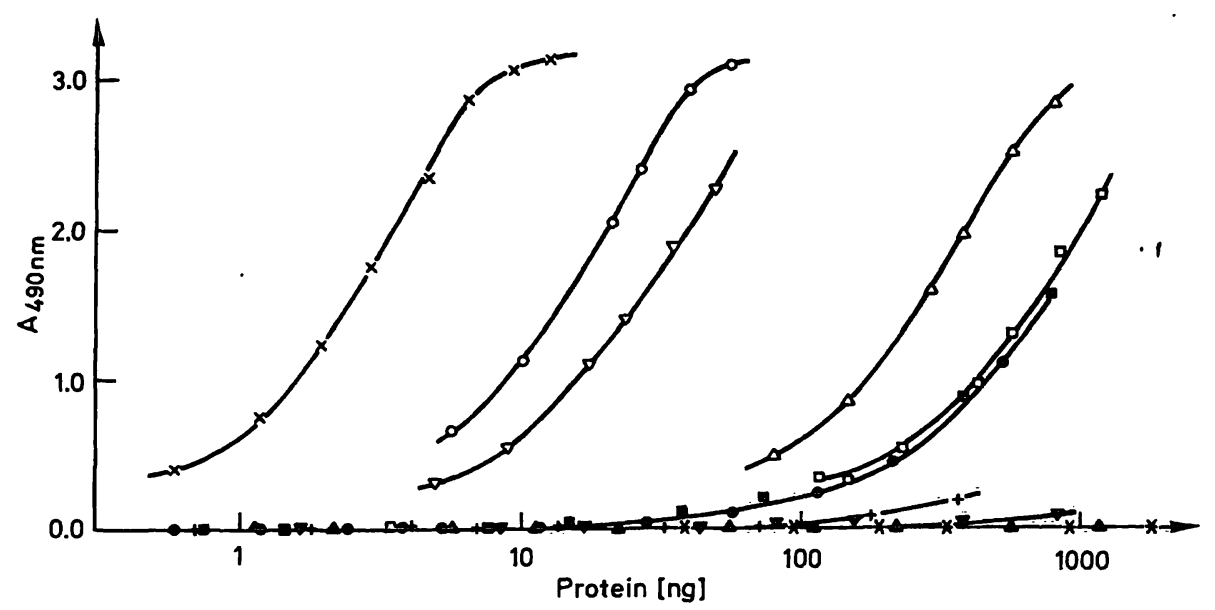

Fig. 2. Standard curves, constructed with purified apolipoprotein C-II ( $\times$ ), chylomicrons ( 0 ), VLDL $(\nabla)$, LDL ( $(\square)$, HDL $(\Delta)$,

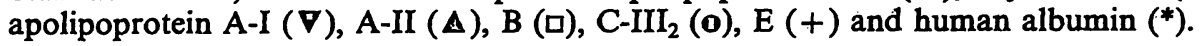

summarised in table 1 , the mean intra- and interassay coefficients of variation were $3.1 \%$ and $7.9 \%$, respectively.

The variation coefficients of 2 controls, determined in 48 consecutive assays, were $4.5 \%$ and $7.2 \%$ for plasma apolipoprotein C-II concentrations of 41.0 and $61.7 \mathrm{mg} / \mathrm{l}$, respectively.

Tab. 1. Assay precision as determined by the coefficient of variation.

\begin{tabular}{lll}
\hline $\begin{array}{l}\text { Apolipoprotein C-II } \\
(\mathrm{mg} / \mathrm{l})\end{array}$ & $\begin{array}{l}\text { Intra-assay } \\
\text { CV \% } \\
(\mathrm{N}=12)\end{array}$ & $\begin{array}{l}\text { Inter-assay } \\
\text { CV \% } \\
(\mathrm{N}=16)\end{array}$ \\
\hline 23.6 & 1.1 & 11.2 \\
41.0 & 4.9 & 5.4 \\
61.7 & 2.6 & 8.2 \\
97.5 & 4.2 & 8.2 \\
147.9 & 2.7 & 6.3 \\
\hline
\end{tabular}

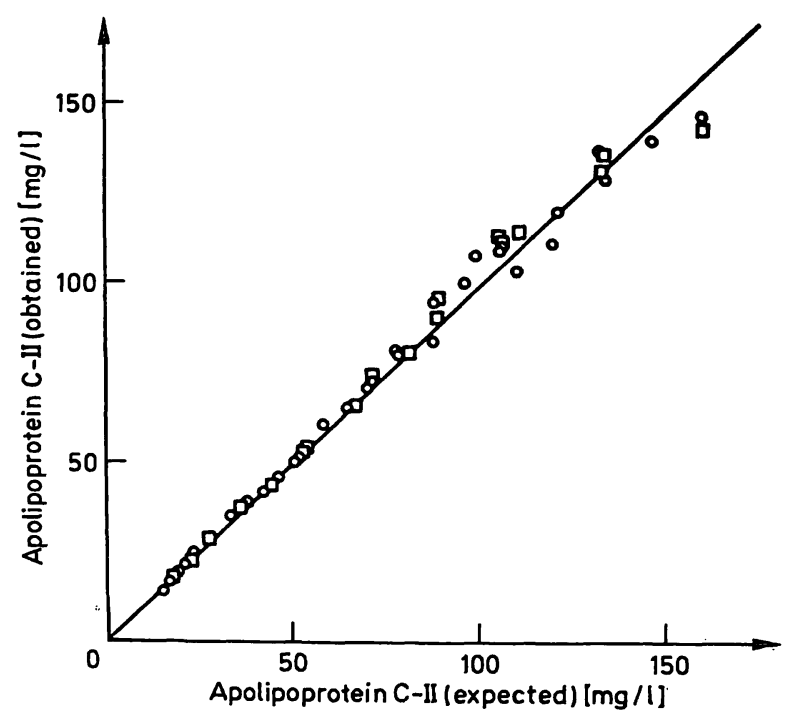

Fig. 3. Correlation between the expected and the obtained apolipoprotein C-II concentrations in the accuracy tests, according to Grannis \& Miller (28).
The assay accuracy was determined by using the admixture technique proposed by Grannis \& Miller (28). Two sets of six artificial plasma samples were prepared by mixing plasma with apolipoprotein C-II concentrations of $20.0 \mathrm{mg} / 1\left(C_{1}\right.$ set $\left.I\right)$ and $23.7 \mathrm{mg} / 1$ $\left(C_{1}\right.$ set II) with a plasma, containing $133.8 \mathrm{mg} / \mathrm{l}$ apolipoprotein $\mathrm{C}-\mathrm{II}$ ( $\mathrm{C}_{6}$ for both sets). In both sets the following admixture ratios were used: $0,20,40,60$, 80 and $100 \%$ of $C_{6}$. Equidisparate specimens were prepared from these mixtures, using dispensing ratios of 1.22 and 1.50 for set I and of 1.50 for set II. As calculated from the known concentrations of $C_{1}$ and $\mathrm{C}_{6}$, and from the admixture and dispensing ratios, the apolipoprotein C-II concentrations obtained by ELISA were $99.6 \pm 4.5 \%(\mathrm{~N}=30$, set I) and 100.5 $\pm 4.2 \%(\mathrm{~N}=18$, set II) of the expected concentrations. The equation of the regression line of expected concentrations $(x)$ versus observed concentrations $(y)$ was $y=0.973^{*} x+2.009$ with a correlation coefficient of $0.994(\mathrm{~N}=48)$ (fig. 3). The mean percentage difference between the observed and the expected concentrations, calculated from the interspecimen sample pairs (equation 4, 1. c. (28)), was $2.48 \pm$ $1.57 \%(\mathrm{~N}=18)$.

\section{Apolipoprotein C-II plasma concentrations}

The apolipoprotein C-II plasma concentrations were determined in 30 normolipaemic and 84 hyperlipaemic subjects (tab. 2). The normal plasma apolipoprotein C-II concentrations, obtained by the proposed sandwich ELISA, were $33.1 \pm 7.5 \mathrm{mg} / \mathrm{l}$. No significant differences were observed between males and females.

As presented in table 2, all hyperlipoproteinaemic subjects had significantly higher.apolipoprotein C-II plasma concentrations than those found for normoli- 
Tab. 2. Plasma apolipoprotein C-II concentrations (mean \pm S.D.) in normo- and hyperlipaemic subjects.

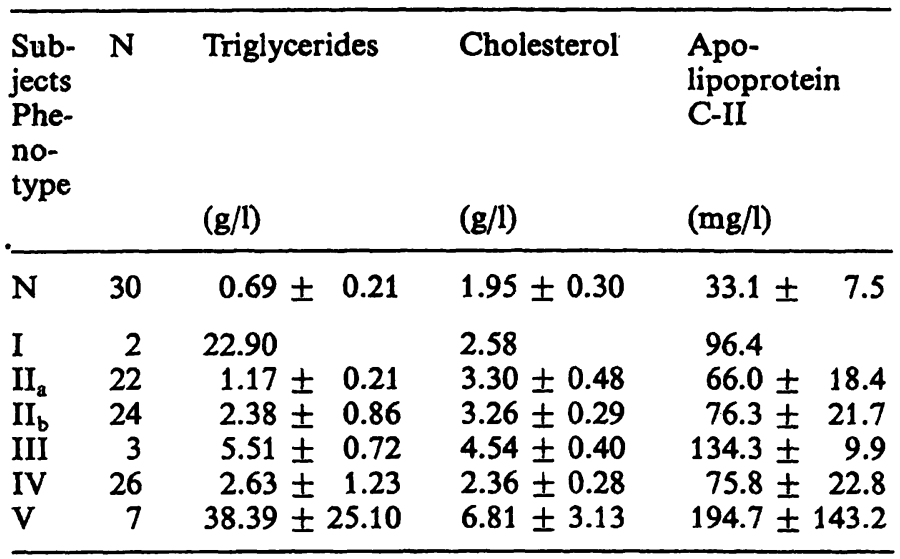

paemic controls $(\mathrm{p}<0.001)$. The mean apolipoprotein C-II levels in Fredrickson type I, type III and type $\mathrm{V}$ patients were respectively 3-fold, 4-fold and 6-fold higher than in normolipaemic controls.

Compared with apolipoprotein C-III (19), the correlation with plasma triglycerides was low $(r=0.37$, $\mathrm{N}=114$ ), due to a negative correlation between apolipoprotein $\mathrm{C}-\mathrm{II}$ and the triglyceride plasma concentrations in Fredrickson type $\mathrm{V}$ patients $(\mathrm{r}=-0.22$, $\mathrm{N}=7$ ). The apolipoprotein $\mathrm{C}$-II plasma concentrations were further significantly $(p<0.01)$ positively correlated with the plasma concentrations of total cholesterol $(\mathrm{r}=0.50, \mathrm{~N}=114)$, apolipoprotein $\mathrm{B}$ $(\mathrm{r}=0.58, \mathrm{~N}=72)$, apolipoprotein $\mathrm{C}$-III $(\mathrm{r}=0.85$, $\mathrm{N}=65)$ and apolipoprotein $\mathrm{E}(\mathrm{r}=0.75, \mathrm{~N}=65)$. A significantly negative correlation was obtained with the concentrations of HDL-cholesterol $(r=-0.53$, $\mathrm{N}=114)$ and apolipoprotein $\mathrm{A}-\mathrm{I}(\mathrm{r}=-0.34, \mathrm{~N}$ $=72$ ). The apolipoprotein C-II/C-III ratio was not significantly correlated with plasma triglyceride concentrations $(r=-0.11, N=65)$. These data are consistent with the values reported by Carlson et al. for a group of 29 normolipaemic subjects (12).

\section{Apolipoprotein C-II distribution}

The apolipoprotein C-II distribution in 6 normolipaemic and 11 hyperlipoproteinaemic subjects, was studied after plasma fractionation by gèl filtration. As shown in figure 4a, all apolipoprotein C-II is lipoprotein-associated and is confined to three lipoprotein subfractions. The first apolipoprotein C-II fraction appears in the triglyceride-rich lipoprotein fraction, while the second apolipoprotein C-II peak appears in fraction II, which is intermediate in size between the triglyceride-rich lipoproteins and the major apolipoprotein B-containing lipoprotein, LDL. This fraction, which is most pronounced in hypertriglycerid-

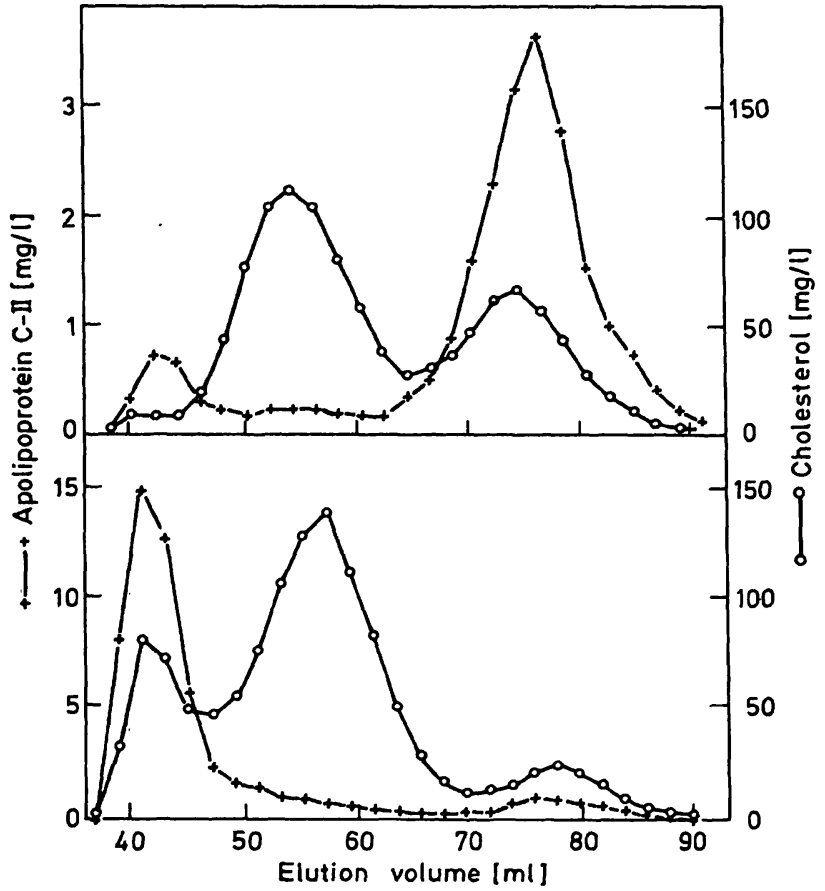

Fig. 4. Apolipoprotein C-II profile in a normolipaemic subject (A) and a hypertriglyceridaemic subject (B). Fresh plasma $(1 \mathrm{ml})$ was separated on a $6 \%$ agarose column and apolipoprotein $\mathrm{C}-\mathrm{II}(+)$ and cholesterol $(0)$ were measured in all fractions.

aemic subjects, coelutes with apolipoprotein C-III (15) and apolipoprotein $\mathrm{E}(18)$, and might therefore represent an intermediate catabolic product of the triglyceride-rich lipoprotein particles (29). Fraction III, which appears as the main apolipoprotein C-II fraction in normolipaemic subjects, coelutes with the apolipoprotein A-I-containing lipoprotein fraction, HDL.

In 6 normolipaemic subjects, fractions I, II and III contained respectively $11.1 \pm 3.7 \%, 11.6 \pm 4.2 \%$ and $76.8 \pm 7.7 \%$ of total plasma apolipoprotein CII. A similar distribution was obtained after fractionation by gradient ultracentrifugation, whereby the $\mathrm{d}<1.030 \mathrm{~kg} / \mathrm{l}, \mathrm{d}=1.030-1.063 \mathrm{~kg} / \mathrm{l}$ and the $\mathrm{d}=1.063-1.021 \mathrm{~kg} / \mathrm{l}$ density fractions contained $8.5 \%, 6.1 \%$ and $78.7 \%$ of total plasma apolipoprotein C-II respectively. Only $2.5 \%$ apolipoprotein CII was lost into the bottom fraction.

As previously shown for apolipoproteins C-III and E $(15,18)$, apolipoprotein C-II redistributes towards the triglyceride-rich lipoproteins in hypertriglyceridaemic subjects. As determined by gel filtration, the triglyceride-rich lipoproteins contained $82.6 \%$

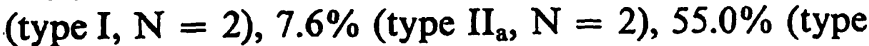
IV, $\mathrm{N}=2$ ) and $89.3 \pm 4.6 \%$ (type $\mathrm{V}, \mathrm{N}=3$ ) of total plasma apolipoprotein C-II. In 2 type III patients, fractions I and II coeluted as 1 peak, containing $49.4 \%$ of plasma apolipoprotein C-II. 
The apolipoprotein C-II distribution, obtained in a Fredrickson type IV patient by either column chromatography or gradient ultracentrifugation were similar. Fractions I, II and III from the gel filtration contained respectively $29.9 \%, 15.4 \%$ and $54.7 \%$ of plasma apolipoprotein C-II. The corresponding fractions, separated by gradient ultracentrifugation contained $36.1 \%, 9.6 \%$ and $52.5 \%$ respectively, while $1.7 \%$ apolipoprotein C-II was lost into the bottom fraction.

From these results a positive correlation $(r=0.73$, $\mathrm{N}=17$ ) was obtained between the percentage of apolipoprotein $\mathrm{C}$-II in the triglyceride-rich lipoproteins, and the total plasma triglyceride concentrations. In terms of absolute values, however, the HDL apolipoprotein C-II concentrations were comparable with those of normolipaemic subjects.

\section{Discussion}

The specific quantitation of human apolipoprotein C-II by immunological assays has been hampered by the difficulties encountered in the isolation of pure apolipoprotein C-II. Using standard techniques, apolipoprotein C-II is inevitably contaminated with apolipoprotein C-III (30). As a consequence, the polyclonal antisera raised in rabbits are not monospecific. Based on a combined use of both an apolipoprotein C-II and an apolipoprotein C-III immunosorbent column, monospecific antibodies to human apolipoprotein C-II could be isolated from rabbit antisera, to produce a monospecific peroxidase-antibody conjugate. The specificity of the sandwich ELISA for apolipoprotein C-II, was demonstrated by the lack of response of apolipoprotein C-III, isolated either by chromatofocussing or by ion exchange chromatography.

The standard curves, constructed with purified apolipoprotein C-II, were parallel to those constructed with plasma and with purified lipoprotein fractions. Delipidation of either plasma or the lipoprotein fractions did not increase the amount of immunoassayable apolipoprotein C-II, thereby indicating a full exposure of the apolipoprotein C-II epitopes to the antisera used in the ELISA assay, under the conditions described under methods.

These data are in good agreement with the reports of Kashyap et al. (6) and Schonfeld et al. (7), whose double antibody RIA could not detect any differences in apolipoprotein C-II plasma concentrations after delipidation. Using an EID assay (9), Curry et al. reported the technical need of delipidation in cases of severe hypertriglyceridaemia. In an INA, Weiswei- ler et al. (11) reported plasma pretreatment with Lipoclean, in order to obtain low background nephelometric readings of turbid samples.

Except for the RIA proposed by Schonfeld et al. (7), using $0.01 \%$ Triton $X-100$ in the assay buffer, no sample pretreatment or additives were used in these apolipoprotein C-II immunoassays. However, Barr et al. reported a $73 \%$ increase of immunoassayable apolipoprotein C-II after plasma delipidation, using a double antibody RIA (8). Similar results were obtained by adding $0.06 \%$ Tween 20 to the assay buffer, whereas Triton X-100 did not influence the plasma apolipoprotein C-II concentrations. Such differences are not readily explained but might originate from the non-standardized use of different antisera as proposed by Barr et al. (8).

As $0.05 \%$ Tween 20 is routinely added to wäshing buffers to decrease the non-specific binding in sandwich ELISA techniques, the results obtained in our assay might be influenced by the presence of this detergent. Deleting the non-ionic detergent from the ELISA assay decreased the apolipoprotein C-II response to $23 \pm 5 \%$. These results suggest that Tween 20 might be necessary in order to fully expose the apolipoprotein C-II epitopes in the proposed sandwich ELISA techique. As suggested from the circular dichroism data of Barr et al. (8), this detergent might release apolipoprotein C-II from its lipoprotein particle.

The mean plasma concentrations of a group of 30 selected normolipaemic subjects $(33 \pm 8 \mathrm{mg} / \mathrm{l})$ was in excellent agreement with the data obtained by Barr et al. (8), who reported a mean value of $34 \pm 11$ $\mathrm{mg} / \mathrm{l}$ in the presence of $0.06 \%$ Tween 20 . Similar values were obtained by Schonfeld et al. (7), using RIA (39 $\pm 14 \mathrm{mg} / \mathrm{l})$, by Curry et al. (9) and by Jauhiainen et al. (10) using EID (respectively $40 \pm$ $20 \mathrm{mg} / 1$ and $40 \pm 7 \mathrm{mg} / \mathrm{l}$ ) and by Weisweiler et al. (11), using immuno nephelometry ( $36 \pm 3 \mathrm{mg} / \mathrm{l}$ ). Slightly higher "normal" plasma values of $50 \pm$ $4 \mathrm{mg} / \mathrm{l}$ were reported by Kashyap et al. (6) using RIA. The lowest "normal" plasma concentrations were reported by Carlson et al. (12), using a competitive enzyme immunoassay $(27 \pm 11 \mathrm{mg} / \mathrm{l})$. As these differences in "normal" apolipoprotein C-II plasma concentrations are rather small, they probably reflect differences in population selection, as suggested by Carlson et al. (12).

In agreement with other reports, $(6-8)$, the hypertriglyceridaemic state is accompanied by elevated plasma apolipoprotein C-II concentrations, reaching a 5- to even 10-fold increase in severe Fredrickson type III and type $\mathrm{V}$ patients. "i 
Due to its activating properties on lipoprotein lipase, apolipoprotein C-II plays a key role in the catabolism of the triglyceride-rich lipoproteins. As these particles are secreted into the vascular compartment, they acquire apolipoprotein $\mathrm{C}$ and apolipoprotein $\mathrm{E}$ from HDL (1). The impaired catabolism of the triglyceriderich lipoprotein particles, results in a permanent redistribution of these exchangeable apolipoproteins and in their accumulation in plasma. As previously demonstrated, the hypertriglyceridaemic state is characterized by high concentrations of apolipoproteins $\mathrm{C}$-III and $\mathrm{E}$ in fraction I, which contains the triglyceride-rich lipoproteins $(13,15,18)$. The analysis of the apolipoprotein C-II profiles obtained from 6 normolipaemic and 11 hypertriglyceridaemic subjects, after plasma fractionation by gel filtration, yielded similar data. The percentage of apolipoprotein CII in the triglyceride-rich lipoprotein fraction was positively correlated with the total plasma triglyceride concentrations $(r=0.73)$.

The parallel behaviour of all exchangeable apolipoproteins was further demonstrated by the positive correlation between the apolipoprotein C-II plasma concentrations and the plasma apolipoprotein C-III and apolipoprotein $\mathrm{E}$ concentrations, with correlation coefficients of $r=0.85$ and $r=0.75$, respectively.

\section{Conclusion}

In conclusion, the sandwich ELISA assay can be proposed as a simple and rapid technique for apolipoprotein measurement. Its easy automation makes it suitable for large screening studies, while its sensitivity enables the study of the changes in apolipoprotein distribution profiles in response to various endogenous and exogenous factors.

\section{Acknowledgement}

We are grateful to Dr. $F$. Belpaire from the Heymans Institute of the state university hospital of Ghent, for raising the rabbit antisera, and to Dr. Marescau from the Department of Neurochemistry of the University of Antwerp for the amino acid analysis. J. Bury was a recipient of an I. W. O. N. L. Fellowship.

\title{
References
}

1. Dolphin, P. J. (1985) Can. J. Biochem. Cell. Biol. 63, $850-869$.

2. LaRosa, J. C., Levy, R. I., Herbert, P., Lux, S. E. \& Fredrickson, D. S. (1970) Biochem. Biophys. Res. Commun. $41,57-62$.

3. Breckenridge, W. C., Little, J. A., Steiner, G., Chow, A. \& Poapst, M. (1978) New. Engl. J. Med. 298, 1265-1273.

4. Jackson, R. L., Baker, H. N., Gilliam, E. B. \& Gotto, A. M. (1977) Proc. Natl. Acad. Sci. USA 74, 1942-1945.

5. Hospattankar, A. V., Fairwell, T., Ronan, R. \& Brewer, H. B. (1984) J. Biol. Chem. 259, 318-322.

6. Kashyap, M. L., Srivastava, L. S., Chen, C. Y., Perisutti, G., Campbell, M., Lutme, R. F. \& Glueck, C. J. (1977) J. Clin. Invest. 60, 171-180.

7. Schonfeld, G., George, P. K., Miller, J., Reilly, P. \& Witztum, J. (1979) Metabolism 28, $1001-1010$.

8. Barr, S. I., Kottke, B. A., Chang, J. Y. \& Mao, J. T. (1981) Biochim. Biophys. Acta 633, $491=505$.

9. Curry, M. D., McConathy, W. J., Fesmire, J. D. \& Alaupovic, P. (1981) Clin. Chem. 27, 543- 548.

10. Jauhiainen, M., Laitinen, M., Penttilä, I., Puhakainen, E. \& Hietanen, E. (1983) Int. J. Biochem. 15, 501-506.

11. Weisweiler, P. \& Schwandt, P. (1984) Fresenius Z. Anal. .Chem. 317, $708-709$.

12. Carlson, L. A. \& Holmquist, L. (1982) Clin. Chim. Acta 124, $163-178$.

13. Bury, J., De Keersgieter, W., Rosseneu, M., Belpaire, F. \& Christophe, J. (1985) Clin. Chim. Acta 145, 249-258.

14. Knipping, G., Steyrer, E., Zechner, R. \& Holasek, A. (1984) J. Lipid Res. 25, 86-91.

15. Bury, J. \& Rosseneu, M. (1985) J. Clin. Chem. Clin. Biochem. 23, 63-68.

16. Bensadoun, A. \& Weinstein, D. (1976) Anal. Biochem. 70, $241-250$.

17. Mills, G. L., Lane, P. A. \& Weech, P. K. (1984) In: A guidebook to lipoprotein technology pp. 266-276. Elsevier Amsterdam New York Oxford.

18. Bury, J., Vercaemst, R., Rosseneu, M. \& Belpaire, F. (1986) Clin. Chem. 32, 265-270.

19. Bury, J. \& Rosseneu, M. (1985) Clin. Chem. 31, 247-251.

20. Rosseneu, M., Vinaimont, N., Vercaemst, R., De Keersgieter, W. \& Belpaire, F. (1981) Anal. Biochem. 116, 204-210

21. Nakane, P. K. \& Kawaoi, A. (1974) J. Histochem. Cytochem. 22, 1084-1091.

22. Hilton, M. A. (1982) Clin. Chem. 28, 1215-1218.

23. Bradford, M. M. (1976) Anal. Biochem. 72, 248-254 (1976).

24. Fredrickson, D. S., Levy, R. I. \& Lees, R. S. (1967) New Engl. J. Med. 276, 32-44; 94-103; 148-156; 215-226; 273-281.

25. Rosseneu, M., Van Biervliet, J. P., Bury, J. \& Vinaimont, N. (1983) Pediatric Res. 17, 788-794.

26. Lowry, O. H., Rosebrough, N. J., Farr, A. L. \& Randall, R. J. (1951) J. Biol. Chem. 193, 265-275.

27. Cham, B. E. \& Knowles, B. R. (1976) J. Lipid Res. 17, $176-181$.

28. Grannis, G. F. \& Miller, W. G. (1976) Clin. Chem. 22, $500-512$.

29. Rubinstein, A., Gibson, J. C., Paterniti, J. R. Jr., Kakis, G., Little, A., Ginsberg, H. N. \& Brown, W. V. (1985) J. Clin. Invest. 75, 710-721.

30. Ronan, R., Kay, L. L., Meng, M. S. \& Brewer H. B. (1982) Biochim. Biophys. Acta 713, 657-662.

\author{
J. Bury \\ Department of Clinical Chemistry \\ A. Z. St-Jan \\ Ruddershovelaan 10 \\ B-8000 Brugge
}


